\title{
Enhanced performance of carbon/carbon supercapacitors upon graphene addition
}

\author{
Sanliang Zhang ${ }^{1} \cdot$ Christina Lum $^{2} \cdot$ Ning Pan ${ }^{1}$
}

Received: 4 January 2017/ Accepted: 24 June 2017 / Published online: 29 June 2017

(C) Springer International Publishing AG 2017

\begin{abstract}
Graphene has great potential for application in capacitive energy storage devices. In this study, we have investigated the effects of employing reduced graphene oxide (rGO) either as an additional supplement or as a total replacement of carbon black, the current conductive additive used in commercial carbon/carbon supercapacitors. We also examined the impact of incorporating rGO before and during the slurry preparation. Some electrochemical and morphological studies were conducted to compare the rGO and carbon black in performance enhancement for conventional activated carbon-based electrodes. Our results have demonstrated the benefits of incorporating graphene into the current carbon/carbon supercapacitors.
\end{abstract}

Keywords Activated carbon - Enhanced performance · Reduced graphene oxide $\cdot$ Supercapacitor

\section{Introduction}

Supercapacitors (SC) are rechargeable capacitive electrical energy storage (EES) devices bridging the gap between dielectric capacitors and batteries. Owing to their ability to store and expend considerable amounts of electricity in relatively short period of time, SCs can be found in a wide array of applications, such as in cranes, wind turbines, airplanes, buses and trams. In addition to their outstanding

Sanliang Zhang

slzhang@ucdavis.edu

1 Department of Biological and Agricultural Engineering, University of California, Davis, CA 95616, USA

2 Department of Chemical Engineering and Materials Science, University of California, Davis, CA 95616, USA power performance, they also demonstrate very long cycle life (>1,000,000 cycles), fit-and-forget benefits and less heat generation compared to other EES devices. These outstanding properties are mainly originated from the basic operating principle of SCs by utilizing high surface area carbons (normally activated carbon in particulate form) to electrostatically accumulate and release electrolyte ions during the charging and discharging processes. Although certain metal compounds and conducting polymers have been explored to faradaically store electricity at electrode surface, activated carbon (AC)-based SCs still dominate the market due to their comparably lower cost, higher power density and longer cycle life. Such merits are mainly stemming from its electrostatic charge storage mechanism, which occurs much faster and more reversible than the faradaic processes for either metal compounds or conducting polymer-based SCs.

To further improve the performance of AC-based SCs, certain amounts of conductive additives have to be added to the AC electrodes so as to enhance their electrical conductivity to fully realize their power performance and maximize their charge storage capacity $[4,20]$. The most commonly used conductive additive is carbon black (CB) for its excellent electrical conductivity. However, carbon black is known for such deficiencies as relatively low packing density, poor electrochemical performance $\left(<5 \mathrm{~F} \mathrm{~g}^{-1}\right)$ [16] and its potential carcinogenic effects.

Possible substitutes for carbon black include carbon onion, metallic carbon nanotube, and graphene. The electrochemical performance of carbon onion has been extensively studied by Gogotsi et al. [16], Pech [11, 13] who reported a specific capacitance ca. $40 \mathrm{~F} \mathrm{~g}^{-1}$ and some electrochemical performance improvement when carbon onion was added to AC electrode. Carbon nanotube has been widely examined as active material for supercapacitor 
electrodes, and its specific capacitance varies from 20 to $130 \mathrm{~F} \mathrm{~g}^{-1}[1,6,7]$. Carbon nanotubes have shown an outstanding electrical conductivity that enables the electrodes to achieve higher power density. However, caution was advised about carbon nanotube by Simon et al. $[14,15,20]$ after some systematically studies of its influence on the electrochemical performance of carbon/carbon SCs. They concluded that addition of carbon nanotube leads to both a lower specific capacitance and smaller energy density. Therefore, both carbon onion and carbon nanotube have been proved to be not practical to replace carbon black.

Graphene, with a specific capacitance varying from 80 to $170 \mathrm{~F} \mathrm{~g}^{-1}[18,23,29]$, has been regarded as a prime carbon form to possibly replace AC in SCs. However, pure graphene-based electrodes so far exhibit low packing density which severely restrains the resulting volumetric energy density, and its cost is expected to be much higher than AC. Consequently, researchers have started to hybrid graphene with AC to produce densely packed supercapacitor electrodes to improve electrochemical performance. There have been two general approaches proposed so far to incorporate graphene in AC electrodes. The first one includes mixing graphene oxide with various biomasses as the carbon source and then producing the AC/graphene composites via hydrothermal or normal activation process $[3,26,27]$. The second method involves synthesizing AC/graphene organogels through thermal reduction of graphene oxide at moderate temperature in an autoclave $[22,27]$. Although there have been some encouraging reports on the improved electrochemical performance of these AC/graphene composites, they are not ready for adoption by the supercapacitor industry because of the high cost due to the inefficient processes. To align better with the current supercapacitor electrode fabrication process, a cost-effective and easy approach has to be developed to incorporate graphene into the carbon/carbon SCs.

Herein, we proposed two simple methods for the first time to incorporate graphene into the current AC electrode fabrication process: (1) adding reduced graphene oxide (rGO) directly into the AC slurry for electrode preparation or (2) producing the $\mathrm{rGO} / \mathrm{AC}$ blend from graphene oxide/ AC solution and then prepare the slurry. A systematic study is then conducted to find the optimal graphene content of rGO for both approaches, in comparison with the conventional electrodes with and without adding carbon blacks. From the testing results, we can demonstrate the feasibility of our approaches and show that the addition of graphene in carbon/carbon SCs is significantly beneficial.

The resultant graphene-added supercapacitor will enable a wider adoption of supercapacitors in various environmental applications. For example, when the supercapacitor is incorporated into the regenerative braking systems, it will help to harvest the power during braking of automobiles, hybrid buses, trams, trains, etc. and later release the stored power to assist the acceleration process, thus reducing the energy consumption and greenhouse gas emission. If used in the blade pitch system of wind turbines, the reliability and stability of the produced electricity to the grid will be greatly improved. It is also suited to the intermittent power firming to alleviate the power fluctuation of the generated electricity from solar or wind farms, which will in turn promote the adoption of solar and wind energies to benefit the environment (Ciccarelli et al. $[2,9]$.

\section{Experimental}

\section{Materials and methods}

In this study, we first prepared graphene oxide (GO) from natural graphite flake (99.8\%, Alfa Aesar, UK) via Hummer's method [8]. Hydrazine hydrate (50-60\%, SigmaAldrich, USA) was then used to reduce the exfoliated GO sheets into reduced graphene oxide (rGO) based on a procedure developed by Ruoff et al. [17]. Commercial activated carbon (AC) (AB-520, MTI Corporation, USA), carbon black (CB) (Super P Conductive, Alfa Aesar, UK), PTFE as adhesive both in water $(60 \%$, Sigma-Aldrich, USA) and in ethylene alcohol (99.8\%, Sigma-Aldrich, USA) were obtained from their respective suppliers and used as received. The AB-520 AC has a BET surface area of ca. $2000 \mathrm{~m}^{2} \mathrm{~g}^{-1}$, a micropore size of 2.0-2.2 nm, and a pore volume ca. $0.9 \mathrm{~cm}^{3} \mathrm{~g}^{-1}$. A highly porous nickel foam with porosity ca. 95\% (MTI Corporation, USA) was used as the current collector, $6 \mathrm{M} \mathrm{KOH}(85 \%$, Sigma-Aldrich, USA) as the electrolyte and cellulose filter paper (Whatman, Grade 1) as the separator for the SCs.

Based on the use of carbon black (CB), two groups of $\mathrm{SCs}$, with and without $\mathrm{CB}$ in the electrode, were constructed. Then within each group, three further different SCs were prepared according to the use of graphene oxide (rGO), so that a total of six kind samples were prepared: (1) the original control samples coded as AC + CB + PTFE, and (2) without $\mathrm{CB}$ (AC + PTFE); (3) samples with rGO reduced alone and with $\mathrm{CB}(\mathrm{AC}+\mathrm{rGO}+\mathrm{CB}+\mathrm{PTFE})$, and (4) without $\mathrm{CB}$ (AC + rGO + PTFE); (5) rGO produced in the present of $\mathrm{AC}$ with $\mathrm{CB}(\mathrm{AC} /$ $\mathrm{rGO}+\mathrm{CB}+\mathrm{PTFE})$, and (6) without $\mathrm{CB} \quad(\mathrm{AC} /$ rGO + PTFE). In all samples, the slurry was prepared in ethanol alcohol with 8 and $7 \mathrm{wt} \%$ for conductive additive and PTFE binder, respectively. The weight percent of rGO in the electrodes was varied from 0 to $20 \%$ to examine its influence on electrochemical performance. Two-electrode symmetric SCs in $6 \mathrm{M} \mathrm{KOH}$ were constructed with 
industrial-level mass loadings of $10-15 \mathrm{mg} \mathrm{cm}^{-2}$. The finished SCs are in the form of CR 2032 button cells.

\section{Performance characterization}

The electrochemical properties of the as-constructed button cells were examined using the following tests: cyclic voltammetric (CV) (Princeton Applied Research, Model 263A), electrochemical impedance spectroscopic (EIS) (EG\&G 263A), and constant current charge-discharge (CCCD) (MTI Corporation, Eight Channel Battery Analyzer) [25]. The specific capacitance, power and energy densities were calculated for a single electrode using the collective mass including that of the conductive additive and polymer adhesive PTFE based on the evaluation scheme proposed by Zhang and Pan in Ref. [24]. More specifically, the specific capacitance was calculated from total capacitance $C_{\mathrm{T}}$ normalized by the mass of both electrodes. The total capacitances $C_{\mathrm{T}}$ was derived from the CV, CCCD and EIS data based on Eqs. (1), (2) and (3), respectively, where $V_{0}$ is the rated operating potential, $V_{\mathrm{IR}-}$ drop is the potential difference at IR drop, $v$ is the scan rate, $i$ is the instantaneous current, $\mathrm{t}$ is the time, $\operatorname{Re}(\mathrm{C})$ and $\operatorname{Im}(\mathrm{Z})$ are the real capacitance and imaginary impedance, respectively. In addition, the computation methods for energy and power densities are also provided in Eqs. (4) and (5), respectively, where $E_{\mathrm{D}}$ is the energy density, $P_{\mathrm{D}}$ is the power density, $R_{\mathrm{ES}}$ is the equivalent series resistance and $\Pi$ is the total mass of both electrodes.

$$
\begin{aligned}
& C_{T}=\frac{\Delta Q}{\Delta V}=\frac{\int_{0}^{2 V_{0} / v}|i| \mathrm{d} t}{2 V_{0}} \\
& C_{T}=\frac{I_{\mathrm{dis}} \times \Delta t_{V_{0}}-2 V_{0}}{V_{0}-V_{\mathrm{IR}-\mathrm{drop}}} \\
& \operatorname{Re}(C)=\frac{\operatorname{Im}(\mathrm{Z})}{\omega|Z|^{2}} \\
& E_{D}=\frac{1 / 2 C_{T} V_{0}^{2}}{3600 \times \Pi} \\
& P_{D}=\frac{V_{0}^{2}}{4 R_{\mathrm{ES}} \Pi}
\end{aligned}
$$

Moreover, scanning electron microscope (SEM, SEI XL30) was used to examine the microstructure of the asprepared electrodes.

\section{Results and discussion}

The electrochemical performance of conventional carbon electrodes $(\mathrm{AC}+\mathrm{CB}+\mathrm{PTFE})$ was first examined via a constant current charge-discharge (CCCD) test, resulting in a specific capacitance of $205 \mathrm{~F} \mathrm{~g}^{-1}$ at a current density of $10 \mathrm{~mA}$ or ca. $6 \mathrm{~mA} \mathrm{~cm}{ }^{-2}$. To determine the effect and optimum graphene loading, the reduced graphene oxide (rGO) with a specific capacitance ca. $135 \mathrm{~F} \mathrm{~g}^{-1}$ [18] was physically added into the system at graphene contents from 0 to $20 \%$ to produce $\mathrm{AC}+\mathrm{rGO}+\mathrm{CB}+\mathrm{PTFE}$ electrodes. The resulting specific capacitance as a function of the graphene content is shown in Fig. 1. According to the rule of mixtures, the resulting specific capacitance should have been between 205 and $135 \mathrm{~F} \mathrm{~g}^{-1}$ when the graphene loading increases from 0 to $100 \%$. However, when the graphene loading is approaching 10\%, the measured specific capacitance peaks at $213 \mathrm{~F} \mathrm{~g}^{-1}$, indicating that a synergistic effect is occurring between rGO and AC. Three potential mechanisms may be at work. Firstly, adding proper amount of graphene into the conventional carbon electrode may have reinforced the electrical conductivity of the whole structure such that the capacitive energy storage ability of activated carbon is better performed. Secondly, the addition of rGO in the form of crumpled graphene sheet into the AC structures may facilitate the migration of electrolyte ions through the electrode, as the rGO sheets produced from a solution process have better electrolyte affiliation than the AC particles that are usually obtained through a high-temperature activation process where the oxygen containing functional groups is largely eliminated [28]. Thirdly, rGO worked more than just as a conductivity enhancer, and it also stored charges itself as an active material, as demonstrated by its much higher specific capacitance $135 \mathrm{~F} \mathrm{~g}^{-1}$ [18] than $\mathrm{CB}\left(<5 \mathrm{~F} \mathrm{~g}^{-1}\right.$ [16]). Consequently, rGO appears to be a promising conductive additive for activated carbon electrodes.

For a closer examination, a graphene content of $8 \%$ was chosen and a CCCD plot of the resulting

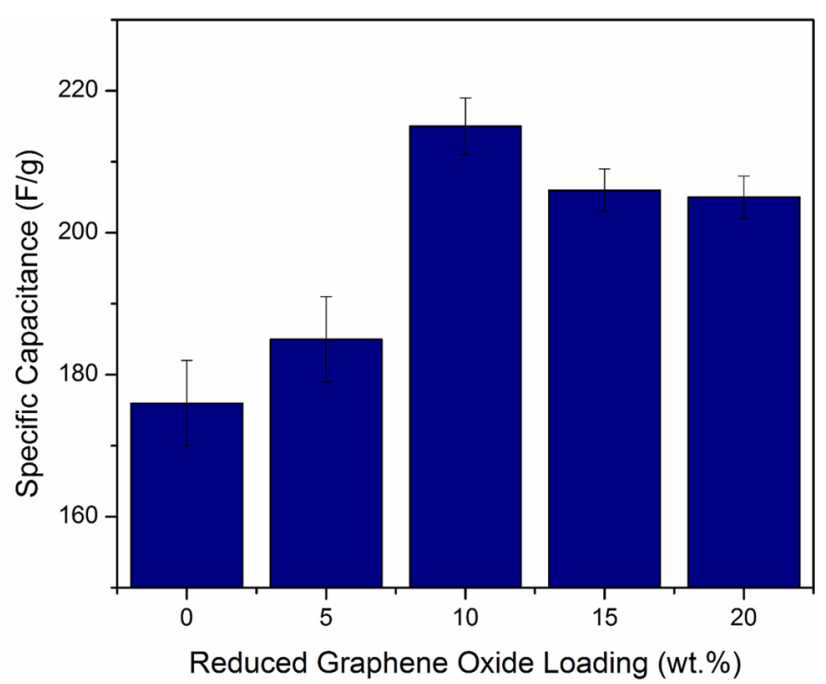

Fig. 1 Specific capacitance of conventional activated carbon electrodes at various graphene loadings from 0 to $20 \%$ 
$\mathrm{AC}+\mathrm{rGO}+\mathrm{CB}+$ PTFE-based $\mathrm{SC}$ is presented in Fig. 2, showing the evolution of both the potential and current with time. The inset plot enlarged the potential change around its peak value of $1 \mathrm{~V}$ and the clearly marked IR drop. The IR drop is an indicator of resistive behavior of the cell and can be used to calculate the equivalent series resistance $\left(R_{\mathrm{ES}}\right)$, which is critical for the power performance of the supercapacitor. A $R_{\mathrm{ES}}$ of $0.97 \Omega$ or $0.57 \Omega \mathrm{cm}^{-2}$ was obtained for the $\mathrm{AC}+\mathrm{rGO}+\mathrm{CB}+\mathrm{PTFE}$ cell, smaller than the $R_{\mathrm{ES}}$ $\left(1.20 \Omega\right.$ or $\left.0.71 \Omega \mathrm{cm}^{-2}\right)$ from $\mathrm{AC} / \mathrm{rGO}+\mathrm{CB}+\mathrm{PTFE}$ cell, and $R_{\mathrm{ES}}\left(1.97 \Omega\right.$ or $\left.1.16 \Omega \mathrm{cm}^{-2}\right)$ from the control sample.

The CV curves of all three supercapacitors in Fig. 3 were rather rectangular, demonstrating negligible difference among them at a scan rate of $10 \mathrm{mV} \mathrm{s}^{-1}$. The $\mathrm{ACl}$ $\mathrm{rGO}+\mathrm{CB}+\mathrm{PTFE}$ cells had slightly larger specific capacitance of $200 \mathrm{~F} \mathrm{~g}^{-1}$ than that of both $\mathrm{AC}+\mathrm{rGO}+\mathrm{CB}+\mathrm{PTFE}\left(197 \mathrm{~F} \mathrm{~g}^{-1}\right)$ and the control samples $\mathrm{AC}+\mathrm{CB}+\mathrm{PTFE}\left(196 \mathrm{~F} \mathrm{~g}^{-1}\right)$. Compared to the specific capacitance in Fig. 1 measured by CCCD test at $10 \mathrm{~mA}$, the CV test at $10 \mathrm{mV} \mathrm{s}^{-1}$ in Fig. 3 here generally gives slightly smaller values, but the general trend is the same in both methods. Moreover, the plots show that the slope of the initial part of the CV curves increased upon the addition of graphene in both $\mathrm{AC} / \mathrm{rGO}+\mathrm{CB}+\mathrm{PTFE}$ and $\mathrm{AC}+\mathrm{rGO}+\mathrm{CB}+\mathrm{PTFE}$ samples, confirming a faster charging process and a smaller $R_{\mathrm{ES}}$ compared to those in the control sample $\mathrm{AC}+\mathrm{CB}+\mathrm{PTFE}$.

Figure 4 presents the Nyquist plots, and the enlarged high-frequency regions (as inset) obtained from EIS test for the three supercapacitors. The equivalent circuit was inserted in the figure where $R_{\mathrm{s}}$ represents the ionic resistance of electrolytes, $R_{\mathrm{ct}}$ is the charge-transfer resistance, $Z_{\mathrm{w}}$ is the Warburg impedance and $C_{\mathrm{dl}}$ is the double-layer capacitance. Collectively, the $R_{\mathrm{ES}}$ was derived based on the

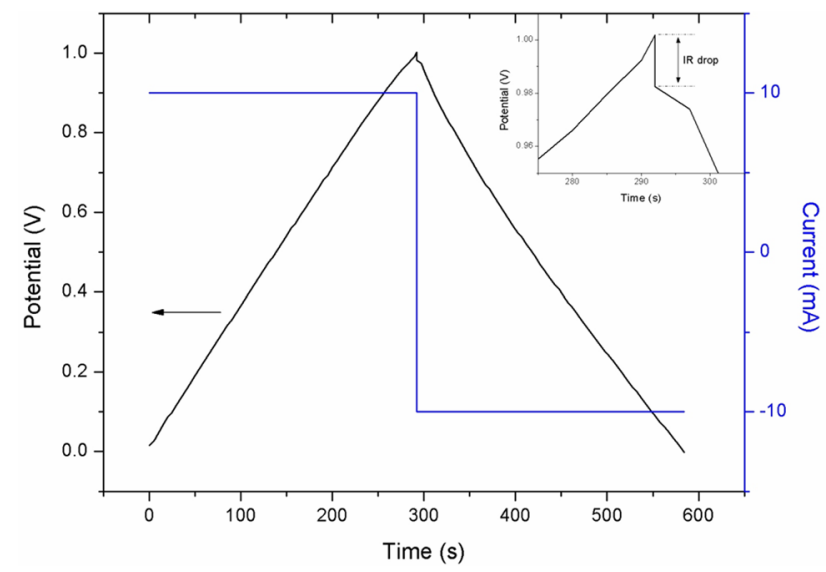

Fig. 2 A typical constant current charge-discharge (CCCD) plot from supercapacitors with $8 \%$ graphene loading

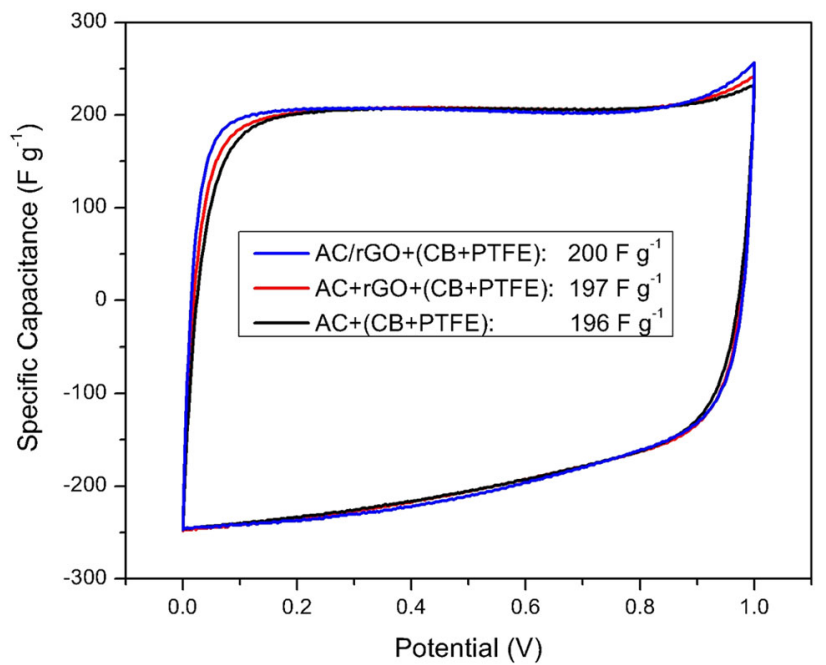

Fig. 3 Cyclic voltammetric (CV) plots at scan rate of $10 \mathrm{mV} \mathrm{s}^{-1}$ of the as-constructed supercapacitors with $8 \%$ graphene loading if present

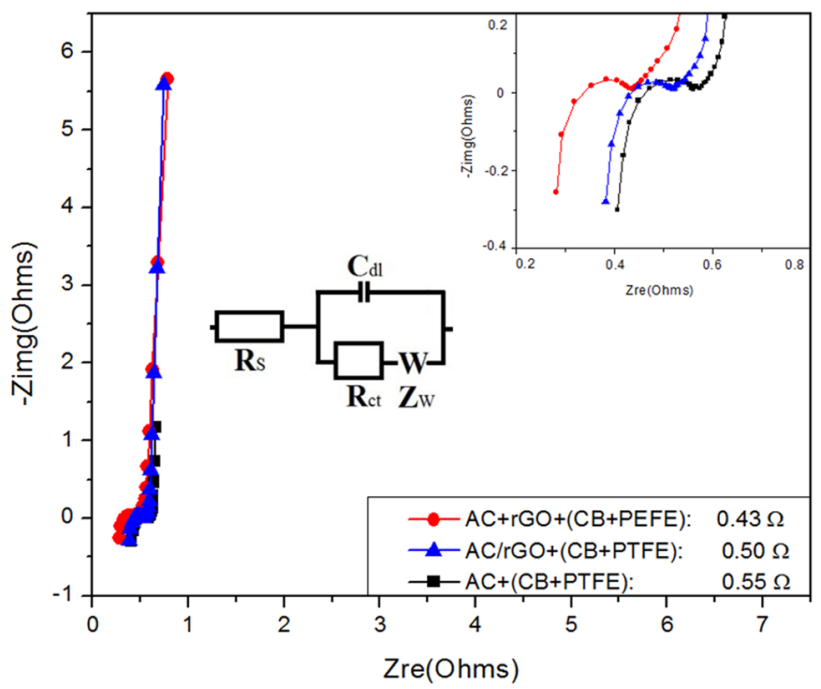

Fig. 4 Nyquist plots of the as-constructed supercapacitors with $8 \%$ graphene loading if present from $0.01 \mathrm{~Hz}$ to $100 \mathrm{kHz}$ with a magnification of the high-frequency region as inserted. Zimg: imaginary part of the impedance; Zre: real part of the capacitance

real part of the impedance at $1 \mathrm{kHz}$ and used to describe the resistance of the supercapacitors. The almost vertical curve at low frequencies suggested near-ideal capacitive energy storage behavior of the cells. A knee frequency [5] at around $385 \mathrm{~Hz}$ was found for all cells, indicating their similar resistive behaviors at different frequencies. This value is very close to the reported knee frequency of activated graphene-based supercapacitors at ca. $382 \mathrm{~Hz}$ [29]. The semicircle at high-frequency region of the Nyquist plot demonstrated a typical Warburg-like behavior resulting from the ion penetration through the porous carbon structure and the electric contact between active 
materials and current collector [17]. Based on the real part of the impedance at $1 \mathrm{kHz}$, the $R_{\mathrm{ES}}$ of the cells can also be estimated. The $\mathrm{AC}+\mathrm{rGO}+\mathrm{CB}+\mathrm{PTFE}$ cell displayed the lowest value of $0.43 \Omega$ or $0.25 \Omega \mathrm{cm}^{-2}$, while the control sample had the largest $R_{\mathrm{ES}}$ of $0.55 \Omega$ or $0.32 \Omega \mathrm{cm}^{-2}$. Compared to the $R_{\mathrm{ES}}$ values obtained from the IR drop of CCCD curves, the Nyquist plots gave much smaller values for the same cells. According to Zhang and Pan [24], although there are more than one ways to derive $R_{\mathrm{ES}}$, the $R_{\mathrm{ES}}$ from the CCCD test was more accurate in describing the resistivity of the cell in actual use and is therefore used in calculating the power density of the carbon electrodes.

According to Simon et al. [19], the cell capacitance of SCs can be computed from the real part of impedance based on EIS data. Therefore, the specific capacitance of the electrodes can be likewise derived this way by simply normalizing the derived cell capacitance. A typical curve describing the change of real and imaginary parts of the specific capacitance versus frequency is shown in Fig. 5 for the $\mathrm{AC}+\mathrm{rGO}+\mathrm{CB}+\mathrm{PTFE}$ cell. From the figure, a specific capacitance of $199 \mathrm{~F} \mathrm{~g}^{-1}$ was obtained, based on the real part of the complex capacitance at the lowest frequency of $0.01 \mathrm{~Hz}$. This value agreed quite well with that calculated from the $\mathrm{CV}$ curve at $10 \mathrm{mV} \mathrm{s}^{-1}$, yet

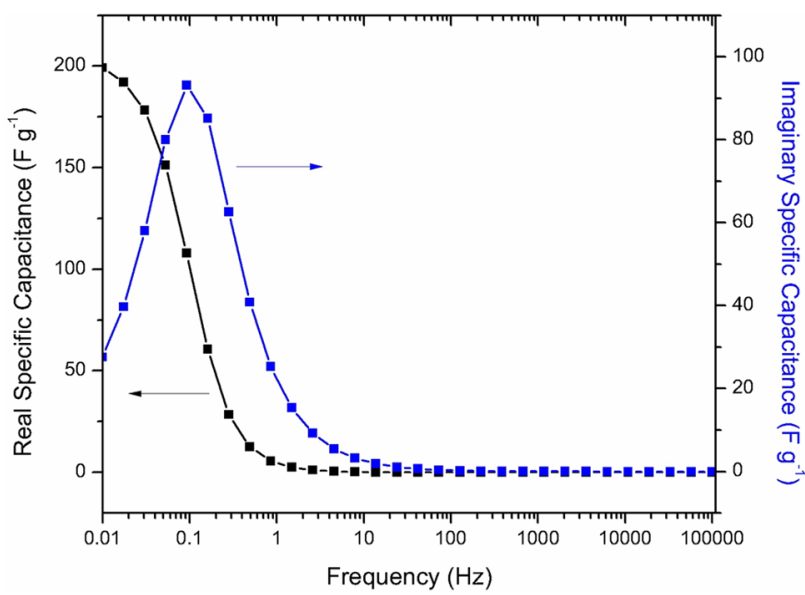

Fig. 5 Evolution of real and imaginary specific capacitance at various frequencies for the cell with $8 \%$ graphene loading smaller than that from the CCCD test. Additionally, a relaxation time constant around $10 \mathrm{~s}$, similar to the value of a cell constructed by Simon et al. [19], was calculated as the reciprocal of the frequency where the imaginary part of the complex capacitance reaches its maximum.

To facilitate further comparison, the above electrochemical properties of the three supercapacitors are summarized in Table 1. Although $\mathrm{AC}+\mathrm{rGO}+\mathrm{CB}+\mathrm{PTFE}$ cell had the lowest $R_{\mathrm{ES}}$ in both CCCD and EIS tests, it is the $\mathrm{AC} / \mathrm{rGO}+\mathrm{CB}+\mathrm{PTFE}$ cell that demonstrated the lowest time constant $\tau$ of $2.20 \mathrm{~s}$ and highest power and energy densities of $6.1 \mathrm{~kW} \mathrm{~kg}^{-1}$ and $7.5 \mathrm{Wh} \mathrm{kg}^{-1}$, respectively, indicating an all-around improvement in performance. It suggests that how the graphene was added into the system will also impact on the final results; rGO reduced in the presence of $\mathrm{AC}$ has generated significantly better energy storage performance than $\mathrm{rGO}$ reduced alone.

Relative to the control cell $\mathrm{AC}+\mathrm{CB}+\mathrm{PTFE}$ $\left(P_{\max }=4.0 \mathrm{~kW} \mathrm{~kg}^{-1}\right.$, and $\left.E_{\max }=7.1 \mathrm{Wh} \mathrm{kg}^{-1}\right)$, the $\mathrm{AC} /$ $\mathrm{rGO}+\mathrm{CB}+\mathrm{PTFE}$ cell achieved a ca. $50 \%$ in power increase with also a slightly higher energy density. Therefore, we can conclude that the incorporation of rGO material into the conventional activated carbon-based supercapacitors is able to significantly enhance the power performance by $50 \%$, without sacrificing the energy performance of the cells. This finding may be very useful in developing next-generation high-performance supercapacitors.

Giving the superior electrical conductivity of graphene material itself, we also constructed another group of button cells to examine the possibility of replacing the carbon black entirely with rGO. The same processes were carried out to produce the supercapacitor electrodes but without adding carbon black at all, and the graphene loading was $8 \%$, the same level as that of carbon black in conventional cells. This no-CB group of cells was tested again, and all the data are provided in Table 2.

If focused on the detailed behaviors of all three cells in Table 2, with the CV curves shown in Fig. 6a, once again the $\mathrm{AC} / \mathrm{rGO}+\mathrm{PTFE}$ cell is superior. From the Nyquist plots in Fig. 6b, similar impedance behaviors are showing for the three cells with tiny difference in $R_{\mathrm{ES}}$. In addition, the cycling stability of the no-CB supercapacitors was

Table 1 Electrochemical performance of conventional activated carbon-based supercapacitors upon graphene addition

\begin{tabular}{|c|c|c|c|c|c|c|c|c|}
\hline & \multicolumn{3}{|c|}{ Specific capacitance $\left(\mathrm{F} \mathrm{g}^{-1}\right)$} & \multicolumn{2}{|l|}{$R_{\mathrm{ES}}(\Omega)$} & \multirow[t]{2}{*}{$\tau(\mathrm{s})$} & \multirow{2}{*}{$\begin{array}{l}E_{\max } \\
\left(\mathrm{Wh} \mathrm{kg}^{-1}\right)\end{array}$} & \multirow{2}{*}{$\begin{array}{l}P_{\max } \\
\left(\mathrm{kW} \mathrm{kg}^{-1}\right)\end{array}$} \\
\hline & $\begin{array}{l}\text { CCCD at } \\
10 \mathrm{~mA}\end{array}$ & $\begin{array}{l}\mathrm{CV} \text { at } \\
10 \mathrm{mV} \mathrm{s}^{-1}\end{array}$ & $\begin{array}{l}\text { EIS at } \\
0.01 \mathrm{~Hz}\end{array}$ & $\begin{array}{l}\text { CCCD at IR } \\
\text { drop }\end{array}$ & $\begin{array}{l}\text { EIS at } \\
1 \mathrm{kHz}\end{array}$ & & & \\
\hline $\mathrm{AC}+\mathrm{CB}+\mathrm{PTFE}$ & 205 & 196 & 196 & 1.97 & 0.55 & 3.17 & 7.1 & 4.0 \\
\hline $\mathrm{AC}+\mathrm{rGO}+\mathrm{CB}+\mathrm{PTFE}$ & 213 & 197 & 199 & 0.97 & 0.43 & 2.86 & 7.4 & 4.7 \\
\hline $\mathrm{AC} / \mathrm{rGO}+\mathrm{CB}+\mathrm{PTFE}$ & 215 & 200 & 201 & 1.20 & 0.50 & 2.20 & 7.5 & 6.1 \\
\hline
\end{tabular}


Table 2 Electrochemical performance of supercapacitors without carbon black

\begin{tabular}{|c|c|c|c|c|c|c|c|}
\hline & \multicolumn{2}{|c|}{ Specific capacitance $\left(\mathrm{F} \mathrm{g}^{-1}\right)$} & \multicolumn{2}{|l|}{$R_{\mathrm{ES}}(\Omega)$} & \multirow[t]{2}{*}{$\tau(\mathrm{s})$} & \multirow[t]{2}{*}{$E_{\max }\left(\mathrm{Wh} \mathrm{kg}^{-1}\right)$} & \multirow[t]{2}{*}{$P_{\max }\left(\mathrm{kW} \mathrm{kg}^{-1}\right)$} \\
\hline & $\mathrm{CCCD}$ at $10 \mathrm{~mA}$ & $\mathrm{CV}$ at $10 \mathrm{mV} \mathrm{s}^{-1}$ & CCCD at IR drop & EIS at $1 \mathrm{kHz}$ & & & \\
\hline $\mathrm{AC}+\mathrm{PTFE}$ & 165 & 155 & 2.20 & 0.77 & 5.97 & 5.7 & 1.7 \\
\hline $\mathrm{AC}+\mathrm{rGO}+\mathrm{PTFE}$ & 214 & 197 & 1.07 & 0.45 & 3.94 & 7.4 & 3.4 \\
\hline $\mathrm{AC} / \mathrm{rGO}+\mathrm{PTFE}$ & 225 & 202 & 1.24 & 0.69 & 3.89 & 7.8 & 3.6 \\
\hline
\end{tabular}
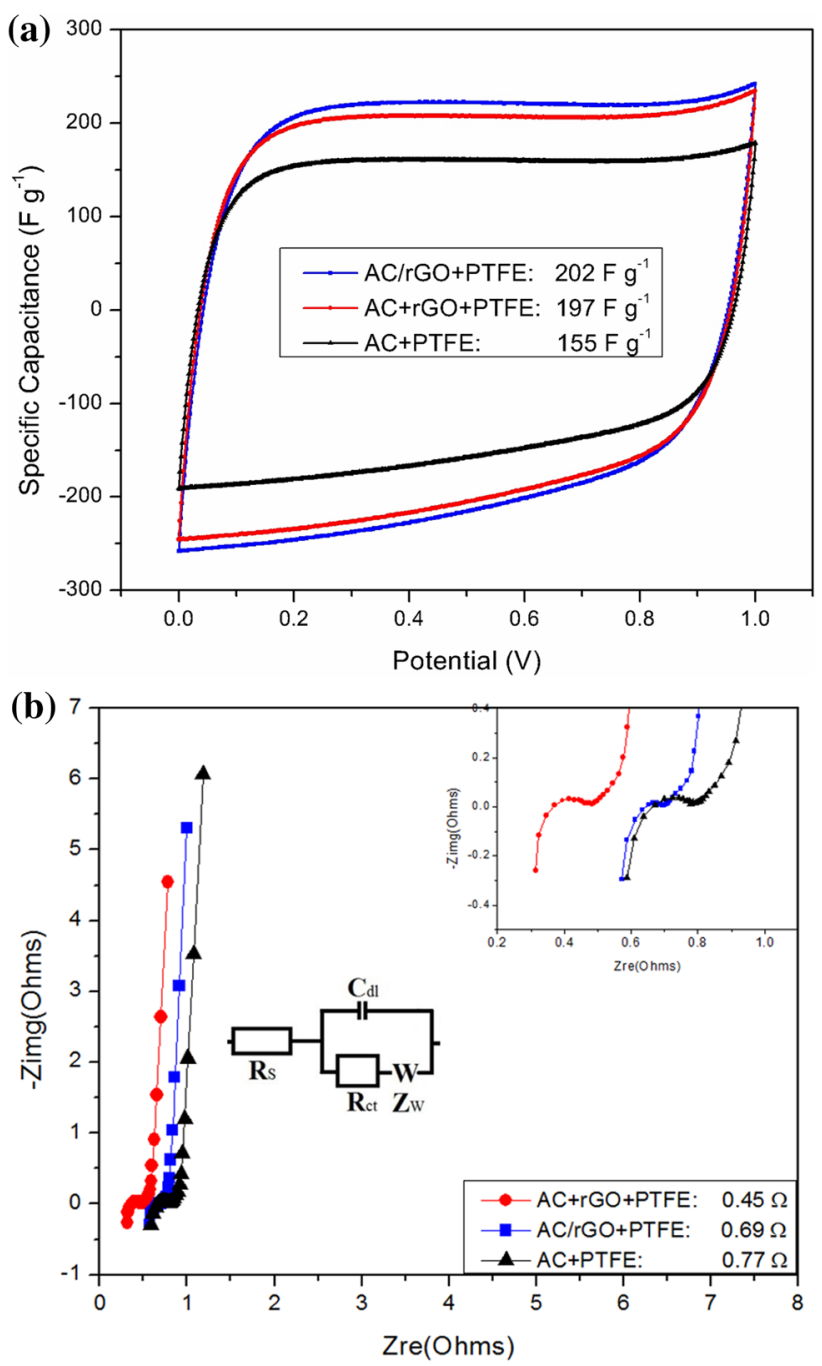

Fig. $6 \mathrm{CV}$ curves at $10 \mathrm{mV} \mathrm{s}^{-1}$ (a) and Nyquist plot with the highfrequency region as inset (b) of the supercapacitors without carbon black

examined via CV test after 5000 consecutive charging and discharging cycles. All of three cells demonstrated superior cycling stability with virtually no decay. Cycling stability and $\mathrm{CV}$ curve comparison are illustrated in Fig. 7 using $\mathrm{AC}+\mathrm{rGO}+\mathrm{PTFE}$ cell as an example. In fact, a tiny capacity increase was observed from the CV curves,

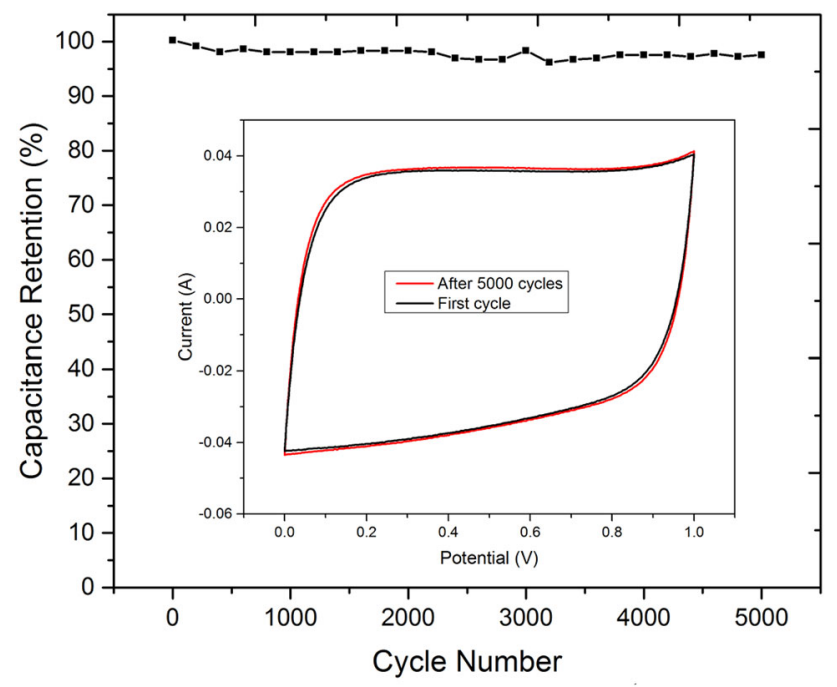

Fig. 7 Cycling stability and $\mathrm{CV}$ curve comparison at $10 \mathrm{mV} \mathrm{s}^{-1}$ after 5000 cycles by using $\mathrm{AC}+\mathrm{rGO}+\mathrm{PTFE}$ cell as an example

indicating improved storage ability after 5000 recharging cycles.

Now if we keep in mind the results for $\mathrm{AC}+\mathrm{CB}+\mathrm{PTFE}$ in Table 1 , the $\mathrm{AC}+\mathrm{PTFE}$ cell in Table 2 shows the poorest performance out of all others. This demonstrated the importance of adding conductive additives, either $\mathrm{CB}$ or rGO, into the activated carbonbased supercapacitor electrodes, since an electrically conductive network is critical for the charge storage of any active material [21].

Similarly, the AC/rGO + PTFE cell demonstrated the largest specific capacitance, $225 \mathrm{~F} \mathrm{~g}^{-1}$ according to CCCD test, a smallest time constant $\tau$, leading to the highest energy and power densities among the three in Table 2. This all-around performance improvement can only be attributed to the addition of rGO, which acted as both a conductivity enhancer and additional energy storage medium. It is interesting to check the effect of replacing $\mathrm{CB}$ with $\mathrm{rGO}$ as the conducing additive by comparing the $\mathrm{AC} /$ rGO + PTFE cell and its counterpart AC + CB + PTFE cell in Table 1: replacing $\mathrm{CB}$ with $\mathrm{rGO}$ improved the energy density from 7.1 to $7.8 \mathrm{Wh} \mathrm{kg}^{-1}$, due to the higher specific capacitance of $\mathrm{rGO}$, but lowed the power density 


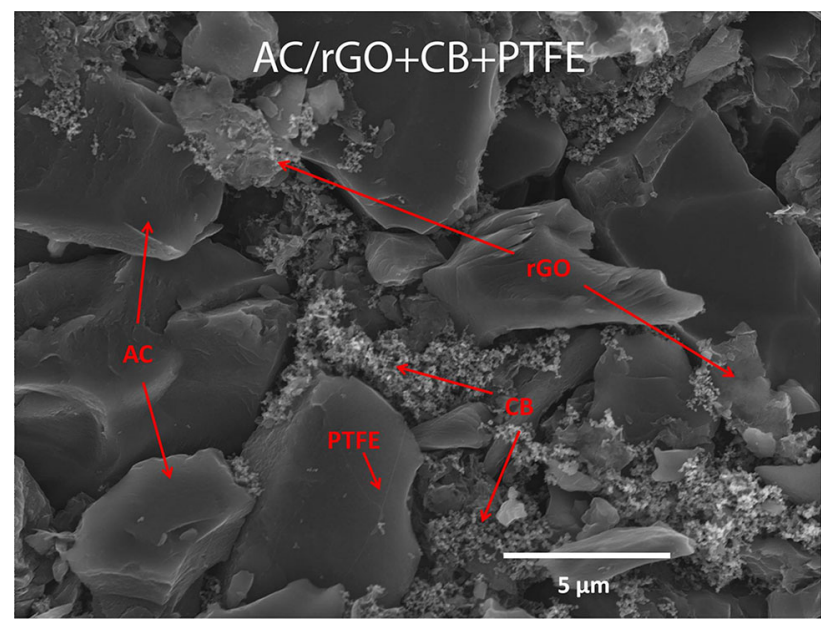

Fig. 8 SEM pictures of the as-prepared $\mathrm{AC} / \mathrm{rGO}+\mathrm{CB}+\mathrm{PTFE}$ electrode

from 4.0 to $3.6 \mathrm{~kW} \mathrm{~kg}^{-1}$, indicating that $\mathrm{CB}$ is a more conducting medium. Moreover, by comparing $\mathrm{AC} /$ rGO + PTFE with AC/rGO + CB + PTFE cells to check the synergy between $\mathrm{AC} / \mathrm{rGO}$ and $\mathrm{CB}$, the $\mathrm{AC} /$ rGO + PTFE cell has slightly higher energy density relative to the $\mathrm{AC} / \mathrm{rGO}+\mathrm{CB}+\mathrm{PTFE}$ one, 7.8 versus $7.5 \mathrm{Wh} \mathrm{kg}^{-1}$ owing again to the better specific capacitance of rGO. Nonetheless, the $\mathrm{AC} / \mathrm{rGO}+\mathrm{CB}+\mathrm{PTFE}$ cell has higher power density $6.1 \mathrm{vs} 3.6 \mathrm{~kW} \mathrm{~kg}^{-1}$, confirming the existence of synergy in electrical conductivity between $\mathrm{CB}$ and rGO.

There were two major reasons for the improved electrochemical performance upon graphene addition with or without $\mathrm{CB}$ : (1) like $\mathrm{CB}, \mathrm{rGO}$ also worked as a conductive bridging material to fill the pores in between the $\mathrm{AC}$ particles; (2) rGO had much higher capacitive energy storage ability than $\mathrm{CB}$. This second claim has already been validated by comparing the reported specific capacitances of $135 \mathrm{~F} \mathrm{~g}^{-1}$ for rGO from Ruoff et al. [18] and $<5 \mathrm{~F} \mathrm{~g}^{-1}$ for CB from Gogotsi et al. [16]. Herein, we examined the "bridging behavior" of $\mathrm{rGO}$ sheets in $\mathrm{AC}$ electrodes by scanning electron microscope (SEM) for $\mathrm{AC} /$ $\mathrm{rGO}+\mathrm{CB}+$ PTFE electrode in Fig. 8, where different structural components were identified and marked. rGO once mixed into the activated carbon electrodes served as a conductive filler to seal the gaps in between the activated carbon particles as shown in Fig. 8, thus improving the electrical conductivity of the electrode structure. Also, rGO sheets could work as a flexible separator to decrease the aggregation of $\mathrm{AC}$ particles and then enhance the pore availability for electrolyte ions [10, 12]. With the improved electric conductive and electrolyte accessible electrode structure, the resulted SC demonstrated superior power and energy performances.

\section{Conclusion}

Given the excellent electronic properties of graphene material, two potential ways are explored in this study to incorporate graphene material into the conventional carbon/carbon supercapacitor for performance enhancement.

The first method is to use the reduced graphene oxide as a supplement, and a $50 \%$ increase in power density was achieved with only $8 \%$ graphene addition. Also by reducing graphene oxide in the presence of activated carbon, slightly higher specific capacitance $215 \mathrm{~F} \mathrm{~g}^{-1}$ and energy density $7.5 \mathrm{Wh} \mathrm{kg}^{-1}$ were obtained. Moreover, reduced graphene oxide was also examined as a possible substitute to replace carbon black. Our results demonstrated a $10 \%$ increase in energy density with a slightly suppressed power performance.

Our analysis confirmed that as a performance enhancer, graphene has much better capacitive energy storage ability yet a little lower electrical conductivity improvement ability relative to carbon black. Overall, incorporating graphene material into the conventional carbon electrodes could be an effective and practical tactic for next-generation high-power supercapacitors, which will prompt wider adoption of supercapacitors in hybrid vehicles and renewables to benefit the environment.

Acknowledgements This work has been supported by California Energy Commission EISG Project 57470A/12-02TE.

\section{References}

1. An KH, Kim WS, Park YS, Moon J-M, Bae DJ, Lim SC et al (2001) Electrochemical properties of high-power supercapacitors using single-walled carbon nanotube electrodes. Adv Funct Mater 11(5):387-392

2. Ball P, Gogotsi Y (2012) Super-capacitors take charge in Germany. MRS Bull 37(09):802-803

3. Chen Y, Zhang X, Zhang H, Sun X, Zhang D, Ma Y (2012) Highperformance supercapacitors based on a graphene-activated carbon composite prepared by chemical activation. RSC Adv 2(20):7747

4. Conway BE (1999) Electrochemical supercapacitor: scientific fundamentals and technological applications. Kluwer Academic/ Plenum Publishers, New York

5. Du C, Pan N (2006) Supercapacitors using carbon nanotubes films by electrophoretic deposition. J Power Sources 160(2):1487-1494

6. Du C, Yeh J, Pan N (2005) High power density supercapacitors using locally aligned carbon nanotube electrodes. Nanotechnology 16(4):350-353

7. Futaba DN, Hata K, Yamada T, Hiraoka T, Hayamizu Y, Kakudate Y et al (2006) Shape-engineerable and highly densely packed single-walled carbon nanotubes and their application as super-capacitor electrodes. Nat Mater 5(12):987-994

8. Hummers W, Offeman R (1958) Preparation of graphite oixde. J Am Chem Soc 80(6):1339 
9. Ciccarelli F, Iannuzzi D, Lauria, D (2011) Supercapacitors-based energy storage for unban mass transit systems. In: Proceedings of the 2011 14th European conference on power electronics and application, Birmingham, pp 1-10

10. Li H, Pan L, Nie C, Liu Y, Sun Z (2012) Reduced graphene oxide and activated carbon composites for capacitive deionization. J Mater Chem 22(31):15556

11. McDonough JK, Gogotsi Y (2013) Carbon onions: synthesis and electrochemical applications. Electrochem Soc Interface 22(3):61-66

12. Nugrahenny ATU, Kim J, Kim S-K, Peck D-H, Yoon S-H, Jung D-H (2014) Preparation and application of reduced graphene oxide as the conductive material for capacitive deionization. Carbon Lett 15(1):38-44

13. Pech D, Brunet M, Durou H, Huang P, Machalin V, Gogotsi Y et al (2010) Ultrahigh-power micrometre-sized supercapacitors based on onion-like carbon. Nat Nanotechnol 5(9):651-654

14. Portet C, Taberna PL, Simon P, Flahaut E (2005) Influence of carbon nanotubes addition on carbon-carbon supercapacitor performances in organic electrolyte. J Power Sources 139(1-2):371-378

15. Portet C, Taberna PL, Simon P, Flahaut E, Laberty-Robert C (2005) High power density electrodes for Carbon supercapacitor applications. Electrochim Acta 50(20):4174-4181

16. Portet C, Yushin G, Gogotsi Y (2007) Electrochemical performance of carbon onions, nanodiamonds, carbon black and multiwalled nanotubes in electrical double layer capacitors. Carbon 45(13):2511-2518

17. Stankovich S, Dikin DA, Piner RD, Kohlhaas KA, Kleinhammes A, Jia Y et al (2007) Synthesis of graphene-based nanosheets via chemical reduction of exfoliated graphite oxide. Carbon 45(7):1558-1565

18. Stoller M, Park S, Zhu Y, An J, Ruoff R (2008) Graphene-Based Ultracapacitors. Nano Lett 8(10):3498-3502
19. Taberna PL, Simon P, Fauvarque JF (2003) Electrochemical characteristics and impedance spectroscopy studies of carboncarbon supercapacitors. J Electrochem Soc 150(3):A292

20. Taberna PL, Chevallier G, Simon P, Plée D, Aubert T (2006) Activated carbon-carbon nanotube composite porous film for supercapacitor applications. Mater Res Bull 41(3):478-484

21. Wu NL, Wang SY (2002) Conductivity percolation in carboncarbon supercapacitor electrodes. J Power Sources 10(1):233-236

22. Yu S, Li Y, Pan N (2014) KOH activated carbon/graphene nanosheets composites as high performance electrode materials in supercapacitors. RSC Adv 4(90):48758-48764

23. Zhang S, Pan N (2013) Supercapacitor performance of crumpled and planar graphene materials produced by hydrogen gas reduction of graphene oxide. J Mater Chem A 1(27):7957-7962

24. Zhang S, Pan N (2015) Supercapacitors performance evaluation. Adv Energy Mater 5(6):1401401

25. Zhang S, Li Y, Pan N (2012) Graphene based supercapacitor fabricated by vacuum filtration deposition. J Power Sources 206:476-482

26. Zheng C, Zhou X, Cao H, Wang G, Liu Z (2014) Synthesis of porous graphene/activated carbon composite with high packing density and large specific surface area for supercapacitor electrode material. J Power Sources 258:290-296

27. Zhou Q, Gao J, Li C, Chen J, Shi G (2013) Composite organogels of graphene and activated carbon for electrochemical capacitors. J Mater Chem A 1(32):9196

28. Zhou Y, Candelaria SL, Liu Q, Huang Y, Uchaker E, CaO G (2014) Sulfur-rich carbon cryogels for supercapacitors with improved conductivity and wettability. J Mater Chem A 2(22):8472

29. Zhu Y, Murali S, Stoller MD, Ganesh KJ, Cai W, Ferreira PJ et al (2011) Carbon-based supercapacitors produced by activation of graphene. Science 332(6037):1537-1541 